\title{
Using an Embedded Conceptual Strategy to Enhance Students' Understanding of Le Chatelier's Summation of Some Stress Factors on Equilibrium Position
}

\author{
Ruby Hanson \\ University of Education, Winneba, Ghana
}

\begin{abstract}
The study aimed to employ small scale science activities to demonstrate and enhance the idea of reversibility of chemical changes in closed systems during chemical equilibrium at the microscopic level among 115 integrated science students. The activities implemented were based on an embedded conceptual change approach. The research tools consisted of two SSS activities on closed systems in equilibrium. Preand post-intervention assessments on chemical equilibrium, 2 SSSE-CBA activities, an observation schedule and a questionnaire enabled the collection of data. The intervention activities lasted for a total of 2 hours in two separate one-hour sessions. Paired samples t-test analysis after the intervention and postassessment revealed that the mean scores of the postconcept assessment (7.94) was statistically higher than that of the pre-concept assessment (4.33) at a significance level of 0.05. Prior to the intervention most students held naïve conceptions about the dynamism of closed systems in equilibrium. However, after the concept-embedded intervention, they gave logical and vivid expressions about systems in equilibrium and how they were affected by external stress, as intimated by Le Chatelier. The results indicated that this intervention could enhance students' conceptual understanding of chemical equilibrium and enable them create mental models.
\end{abstract}

\section{Introduction}

Though students unconsciously come to class with their own conceptions about natural phenomena [1], it is common knowledge that learners often construct knowledge through teachers' expert facilitation and tuition. However, lapses in teachers' expertise in knowledge transmission and facilitation could lead to the formation of misconceptions (herein called alternative concepts) in science, and chemistry classes. The occurrence of the formation of alternative concepts (ACs) is especially true for chemistry as it is rulegoverned [2] and its lessons involve many learning paths such as the acquisition of manipulative, concept, process, problem solving, reflective, time management, analytical, and relational skills, to name a few, all at one time through the use of complex, yet fragile, science equipment and inappropriate teaching methods.
Due to this complexity, teachers' lack of content knowledge and ineptitude in organising concept-based activities could inadvertently cause the development of alternative conceptions (ACs). This implies that, student-teachers (herein called teacher trainees) must master science concepts, as well as innovative ways of teaching them so that the vicious cycle of teacher-made misconceptions could be broken with their students.

Science, and chemistry in particular, is a practical discipline where activities are regularly performed by students for first hand observation and acquisition of concepts and skills. However, the cost of standard (conventional) equipment prevents many teachers from engaging their students in hands- and minds-on activities. They therefore resort to inappropriate teaching methods such as lectures and demonstrations [3]. In order to avert cost and introduce other interactive teaching strategies, Haider and Al-Naqabi [4] used innovative metacognitive strategies to assess and enhance students' understanding of stoichiometry in the United Arab Emirates. Zakaria, Latip and Tantanayon [5] used micro equipment to create an awareness about the concept of pollution. Bilgin, Uzuntiryaki and Geban [6] used various teaching styles to enhance conception about chemical equilibrium. Locaylocay [7] also employed diagnostic concept tests to identify and correct students' alternative conceptions of the topic, chemical equilibrium in the Philippines by using conceptual strategies.

After a 2-tiered diagnostic test on chemical equilibrium was administered to 104 second year teacher trainees in an educational institution in Ghana, it was observed that as many as $31 \%$ had about 11 alternative conceptions [8]. The most common alternative conception was "when a system reached equilibrium no further changes occurred, even if external stress such as change in concentration, volume or temperature were introduced'. It was reiterated in the study that for adult learners who were unable to operate at the micro (particulate) and representational levels abstractly, employing concrete interactive activities would be useful in order for them to form scientific concepts through personal experiences. According to Yildirim, Kurt and Ayas [9] another reason for both adult and young learners not being able to conceptualise chemical equilibrium could be traced 
to inefficient teaching methods such as lectures or copying of notes. They intimated that, learners must be able to see images or imagine in a logical concrete manner, the changes that take place at the moment of equilibrium. They must be able to imagine such changes at the macro, micro, and symbolic levels in order to conceptually understand the topic. In order to facilitate the use of the conceptual approach to help learners to distinguish between stress effects associated with equilibrium and to apply them in their understanding of the concept, simple activities are suggested to facilitate the formation of required images [8]. The small scale science equipment (SSSE) manufactured by Centre for Research and Development in Mathematics, Science and Technology Education (RADMASTE) in South Africa were identified for use. Thus, this current study which employed embedded concept-based activities (CBA) was a follow up to the earlier baseline study on the understanding of chemical equilibrium among teacher trainees.

The use of embedded CBA provides a platform to identify and specify students' misconceptions, clarify naïve reasons and make it possible for them to appreciate why they may not be deemed as good. This concept is based on the constructivists' theory. Students with apparent sound conceptions go through the same process, irrespective of their seeming scientific or logical reasons, for re-affirmation of their conceptual underpinnings of principles. In embedded concept-based activities, several questions are put forth by a teacher or facilitator to enable students to refute or affirm their own prior thoughts in a sequential manner. In a way, they are unconsciously directed to selfquestion, see inadequacies or otherwise of their prior thoughts and re-test what they think is the 'truth' and best option, often through several self-designed or guided approaches. Through these steps, new scientific theories suddenly, and with renewed understanding and gusto, dawn upon learners hard enough to make them refute their old, weak, illogical ideas. This is what is known as insightful learning. Insight learning is the abrupt realisation of a problem's solution. It is a complete cognitive experience that requires the ability to envisage a problem and its solution internally - in the mind's eye, so to speak - before initiating a behavioural response, which is often positive and rewarding. It often results in a long-lasting change. Following the occurrence of insight, the realisation of how to solve the problem can be repeated in similar situations. This present study in a Ghanaian university used directed activities (but not too obvious) to create awareness and in-depth understanding of chemical equilibrium and factors which affect it.
Chemical equilibrium is a state in which the rate of a forward reaction equals the rate of a backward reaction. In other words, in such a state, there is no net change in concentrations of reactants and products. Thus, this kind of equilibrium is said to be dynamic. Chemical equilibrium is about the behaviour of species which undergo unending reversible reactions in a closed system, while Le Chatelier summarises how such systems are affected by stress. He surmises that, if conditions change, the 'equilibrium position' could lie more to one sideeither the right or left of the equation. In this case, properties of the substances present in the equilibrium mixture would change. Questions which were set up to guide the current study were:

1. What concepts do teacher trainees have about the Le Chatelier principle?

2. What skills would trainees demonstrate through activities to depict their understanding of the Le Chatelier concept?

3. What types of concepts would emerge out of trainees' engagements with the SSSE-CBAs?

4. What attributes of the CBAs and SSSE enhance conceptualisation?

\section{Conceptual framework}

In this embedded conceptual change approach activity a six-step model [10] was adopted to commit learners to a position for which they had to take responsibility with justification.

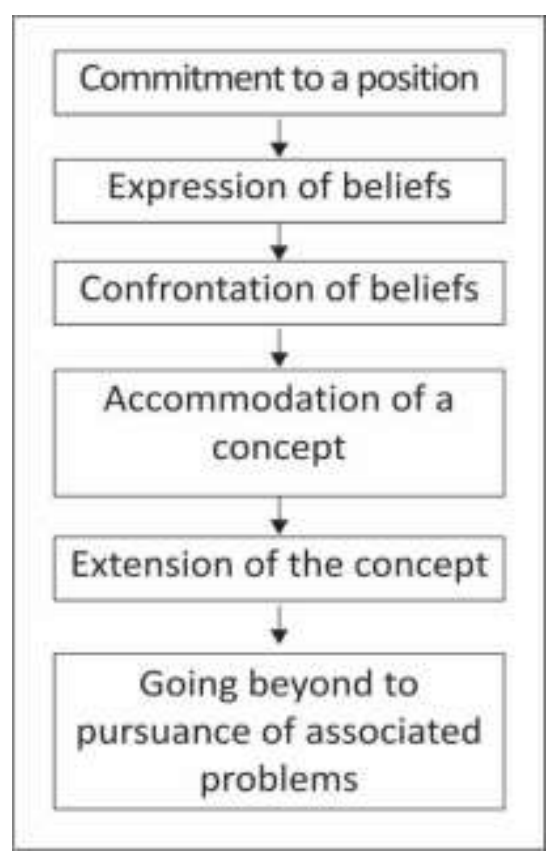

Figure 1. An embedded model for conceptual change 
A platform was thus, created for the exposition of their intentions, beliefs and expectations by discussing their ideas and reasoning with their colleagues before they actually plunged into an investigative activity. They had to confront their beliefs as they worked with materials, collaborated with friends, consulted resources and battled with issues that challenged their prior conceptions. With re-arrangement of ideas, based on available data, observations and outcomes, they accommodated new ideas and incorporated them 'favourably' on existing ones which perhaps were not discarded completely. The adopted conceptual change model is shown as Figure 1.

The model in Figure 1 allows connections between new skills or concepts and extension of newly acquired concepts for favourable outcomes. This creates 'true foundational learning' for the 'aha' (insightful) theory to come alive.

\section{Methodology}

An Action Research with an experimental approach was adopted. A pre-intervention exercise (Appendix A), was administered to a total of 115 science teacher trainees who were an intact course group and purposely selected to engage in two embedded Concept-Based Activities (CBAs) on chemical equilibrium. The trainees were engaged in a whole class discussion after a paper and pen pre-intervention assessment on chemical equilibrium. After the discussions, the trainees engaged in the CBAs which required the use of small scale science equipment (SSSE), copper nitrate $\left(\mathrm{Cu}\left(\mathrm{NO}_{3}\right)_{2} \cdot 3 \mathrm{H}_{2} \mathrm{O}\right), 11 \mathrm{M} \mathrm{HCl}$, a microburner, ice (cold) water, and room-temperature tap water to enable them build their own scientific summations about the effect of stress on equilibrium position. The validated step-wise CBA-SSSE activities with a Cronbach alpha reliability of 0.70 are presented as Appendix C. How the trainees developed lab, process and concept skills were observed with the aid of a validated observation schedule (reliability being $72 \%$ ). A post-intervention assessment, as well as an opinion questionnaire were administered at the end of the activities to assess trainees' impressions about the CBA and SSSE and how they affected their conceptual understanding about Le Chatelier's principles (shown in Appendices E and F respectively).

\subsection{Procedures}

\section{CBA 1: The effect of concentration changes on equilibrium position}

CBA 1 subtly exposed the trainees to the formation of their own concepts about the effect of change in concentrations of reactants and products in an equilibrium mixture on equilibrium position in the reaction:

$\left.\left.\mathrm{Cu}\left(\mathrm{H}_{2} \mathrm{O}\right)_{4}{ }^{2+(} \mathrm{aq}\right)+4 \mathrm{Cl}^{-}(\mathrm{aq}) \rightleftharpoons \mathrm{CuCl}_{4}{ }^{2-(} \mathrm{aq}\right)+$
$4 \mathrm{H}_{2} \mathrm{O}(\mathrm{l})$

In this activity, drops of $\mathrm{HCl}(\mathrm{aq})$ and water were added to a named Well in a plastic RADMASTE comboplate containing a mixture of the species in the equilibrium equation above. Trainees were to predict the shifts in equilibrium by observing changes in colour of the equilibrium mixture upon the addition of excess $\mathrm{HCl}$ (aq) and water. After they answered questions on the activity, they engaged in an extension question in which they had to choose from a list of given reagents, the one which would give the same colour change as with $\mathrm{HCl}$ and explain the chemical principle behind their choice.

\section{CBA 2: The effect of temperature on equilibrium position}

This second activity further extended the trainees' understanding about the effect of change in external conditions on equilibrium. They dipped hot and cold rods into the solution which contained a mixture of the equilibrium reactants. Through follow up questions, they had to explain the effect of temperature on equilibrium position by using only observed colour changes with each action. How knowledge was developed and acquired was observed by means of a validated observation schedule.

\section{The Observation schedule}

The observation schedule (Appendix D), unlike most common observation profiles, was designed to assess trainees' practices and not teachers. Its focus was mainly on how aspects of the activity were executed and if expected or desired learning skills were developed and exhibited at various stages of the CBAs. It was to find out at first-hand how coherently trainees discussed their outcomes and drew logical conclusions from observations. This schedule was based on measurement of alertness [11] and ability to use evidence to generate knowledge. The framework for this instrument was the student-mediating paradigm, which maintains that students actively process information and interpret classroom reality to form concepts [12]. This paradigm enables a researcher to collect students' classroom process data in the context of on-going instructional learning processes. Thus, the Researcher and three trained assistants focused on individuals and groups of trainees for about 30 seconds each and recorded their observations which were 
pooled for the purposes of validation and reliability, which came out to be 0.68 and 0.70 respectively, in this study.

\section{Post-assessment}

A post-intervention assessment (Appendix E) which contained validated questions similar to the preintervention exercise was administered to trainees to assess their understanding of chemical equilibrium after the concept-based practical intervention. After their submission, the post-assessment items were discussed as a whole class activity. The results were compared with that from the pre-intervention and analysed statistically. Both assessments were scored over ten (10) marks each.

\section{CBA-SSSE Opinion questionnaire}

The impact of the CBA through the use of SSSE on trainees were assessed through a questionnaire which comprised 10-close-ended items and one-open ended item (see Appendix F). Its validity and reliability were pre-determined to be 0.72 and 0.70 respectively. A Likert scale which ranged from an increasing value of desires from one (1) to five (5), where 1 = strongly disagree and $5=$ strongly agree was used to gather trainees' opinions about the intervention. It assessed trainees' gain in knowledge and changes in their lab skills.

\subsection{Results and discussion}

Students have various conceptions about chemical equilibrium, some of which may be preconceived notions, non-scientific beliefs, conceptual, vernacular, and factual misconceptions [13]. Most of the erroneous conceptions identified in the trainees' diagnostic preintervention exercise were preconceived misconceptions and conceptual misunderstandings. Some of these were similar to the conceptions expressed in a diagnostic test in a preliminary study [8]. These findings go to buttress that from Taber and Tan [1] that students come to class with their own conceptions about natural phenomena. Some of the trainees' conceptions in the pre-intervention exercise are presented below, with detailed responses in Appendix B.

1. Increasing concentration will shift the equilibrium to the place where concentration is less because they must balance

2. Increase in concentration of reactants means that the reaction will reach equilibrium faster.
3. Decreasing temperature lowers reaction rate. Particles will not collide. Reaction could cease

4. Concentration and temperature changes do not affect equilibrium position and its constant.

However, after participants' engaged in the CBA with the RADMASTE SSSE their perceptions changed, so that they were able to explain that:

1. For a system in equilibrium a colour change could indicate the species in greater concentration, and subsequently the shift in equilibrium position and not its constant.

2. Change in temperature affects the concentrations of species in an equilibrium mixture, which result in colour changes based on shifts in equilibrium because the concentration of some reactant may reduce or be formed in excess to accommodate the new change.

3. Colour change results only when the concentration of one of the coloured species in an equilibrium mixture is affected.

4. The position of equilibrium will change and move in such a way to undo a change one makes.

An interpretive study of the trainees' responses, before and after the CBA activities reveal some factors that contribute to students' alternative conceptions about chemical equilibrium. They learn in their titrimetry course that when concentrations of reactants are altered, they do not affect mole ratios in chemical reaction equations. They also learn about the effects of limiting reagents during their study of stoichiometry, energetics and reaction rates. However, these reactions occur supposedly in open systems. For example, if nitrogen gas and hydrogen gas should react under appropriate conditions in an open system, ammonia gas would be formed, without giving back the reactants. Again, if aqueous sodium hydroxide and hydrochloric acid should react, then sodium chloride and water would be formed. This was clearly a pre-conceived notion about chemical changes. That is, students focus on one-way reactions almost all the time. However, in chemical equilibrium, closed systems are considered and so the propensity of products to act as reactants to yield the original reactants as new products is possible. Two-way or reversible reactions are considered in chemical equilibrium. Inability to fully understand these concepts lead to conceptual misconceptions. However, these basics, and the principle of dynamism, must first be understood before students can appreciate 
equilibrium shifts in dynamic reactions. Students fail to understand that equilibrium positions could change with alterations in reactant and product concentrations which are non-solid, for specific reactions under stated conditions. Many of such conceptual misunderstandings were identified among the teacher trainees in this study.

In this study, trainees could not fully comprehend the effect of additional reactants or products on systems or the effect that an imposed stress could have on a system with respect to equilibrium shifts before the CBA-SSSE interventions were implemented. They had their own vernacular interpretation of the word dynamic. They interpreted it as lively, active, strong and forceful, in the whole class discussion after their pre-assessment. These were literal everyday explanation for dynamism and not as interpreted with respect to chemical equilibrium. They could also not comprehend that in a closed system products could react to give back the reactants. Neither could they rationalise that the shifts occurred in directions that relieved stress so that equilibrium constant could be unaffected. It was also clear that there were deficient connections between knowledge of understanding and their models, representations and explanations. Their answers also indicated their lack of ability to analyse and reflect on questions put to them or answers that they gave. It was therefore important to create opportunities for the trainees to perform activities that would make them systematically reflect on their activities with their colleagues to develop scientific concepts.

The trainees were subtly led through activities to innately understand that there were logical ways of reasoning (from first principle) than following algorithmic paths and procedures which they did not understand. This activities which required carefulness, accuracy and precision on the part of trainees was geared towards the development of manipulative, concept, process and deductive skills. During their activities, trainees found that when 5 to 6 drops of $11 \mathrm{M}$ $\mathrm{HCl}$ were added to a specified Well, $\mathrm{A}[2]$, which contained the equilibrium mixture, its initial blue colour changed to yellowish-green. They observed that the formation of $\mathrm{CuCl}_{4}{ }^{2-}$ (aq) from excess $\mathrm{Cl}^{-}$ions was responsible for the colour change because when more water was added to Well A[2], the yellowish green solution changed to blue to accommodate the excess water. Their deduction was that the presence of $\mathrm{Cl}^{-}$ ions increased the concentration of $\mathrm{CuCl}_{4}{ }^{2-}(\mathrm{aq})$ ions, while that of the $\left.\mathrm{Cu}\left(\mathrm{H}_{2} \mathrm{O}\right)_{4}{ }^{2+(} \mathrm{aq}\right)$ ions decreased. Thus, $\mathrm{CuCl}_{4}{ }^{2-}$ (aq) ions were responsible for the yellowishgreen colour of the solution, while $\mathrm{Cu}\left(\mathrm{H}_{2} \mathrm{O}\right)_{4}{ }^{2+}(\mathrm{aq})$ ions were responsible for the blue colour of the solution. This was because $\mathrm{CuCl}_{4}{ }^{2-}$ (aq) ions was formed in excess to accommodate the excess chloride ions which were introduced from $\mathrm{HCl}$, while $\mathrm{Cu}\left(\mathrm{H}_{2} \mathrm{O}\right)_{4}{ }^{2+}(\mathrm{aq})$ was formed with the introduction of excess water molecules. They supported their assertions with a representative equation and the accompanying displayed colours:

$$
\begin{aligned}
& \mathrm{Cu}\left(\mathrm{H}_{2} \mathrm{O}\right)_{4}{ }^{2+}(\mathrm{aq})+4 \mathrm{Cl}^{-}(\mathrm{aq}) \rightleftharpoons \mathrm{CuCl}_{4}{ }^{2-}(\mathrm{aq})+4 \mathrm{H}_{2} \mathrm{O}(\mathrm{l}) \\
& \text { Blue Colourless Yellowish-green Colourless }
\end{aligned}
$$

In an extended exercise, trainees had to choose from a list of given reagents, the one that could possibly cause a similar change from blue to a yellowish-green colour as in the activity that they had performed. More than half of the sample (98, which translates to $85 \%$ trainees) chose reagents that had $\mathrm{Cl}^{-}$ ions over reagents that had $\mathrm{SO}_{4}{ }^{2}, \mathrm{NO}_{3}^{-}$and $\mathrm{OH}^{-}$anions. They went on to explain their non-choices and choices that an ion like $\mathrm{OH}^{-}$would not alter the initial blue solution while other anions than the chloride could result in other colours. They further added that addition of a solution with $\mathrm{OH}^{-}$ions would form $\mathrm{Cu}\left(\mathrm{H}_{2} \mathrm{O}\right)_{4}{ }_{4}^{2+}$ in the presence of $\mathrm{Cu}^{2+}$ ions which would result in a blue colour. A few trainees attributed the observed colour changes to reasons such as colours of visible light, wavelength, and types of ligands and their effects, which were really not required and could confuse the re-structuring of the desired concepts; nevertheless, these answers indicated that the trainees were now exhibiting analytical and reflective skills by attempting to ascribe reasons for their observations. The way trainees used change in colour to explain the phenomena of Le Chatelier's summation of stress effects show that they were able to understand the forms and functions of the stress factors as well as the relationships between the operating concepts within the macro and symbolic levels. The trainees did not have this level of understanding at the beginning of the study, as can be perceived from their naïve responses to items in the pre-assessment; a suggestion that prior to the study, many trainees had limited experience in the use and interpretation of visible and vivid representations. The study supports the argument of Hanson [8] that students must be engaged in simple, yet expressive and easy to interpret activities, which will help students to form mental imageries that will facilitate their interpretation of chemical changes.

In answer to the focus question for the activity, about $75 \%$ (86) of the trainees asserted that, with respect to the equation given them, addition of either $\mathrm{Cl}^{-}$or $\mathrm{OH}^{-}$ions reflected an equilibrium shift with an accompanying colour change in order to keep Kc constant, in accordance with Le Chatelier's principle. They added that a colour change always reflected the ions in greater concentration or the direction of 
equilibrium shift. A few others stated that $\mathrm{HCl}$ was a limiting reagent; an idea that they imported from stoichiometry. However, it was wrongly applied in their situation and so remediation was given during a whole class discussion. This wrong application suggested that trainees did not fully understand the idea of a 'limiting reagent' and what it truly meant, nor when to apply it. They had the idea of 'dynamism' correct but could not understand that species had to readjust themselves in the presence of external stress to keep Kc constant. Most of their erroneous conceptions could be classified as vernacular misconceptions, preconceived notions and conceptual misunderstandings, which had been identified by Hanson [8] as emanating from inappropriate teaching methods, teacher's own incompetence, and misinterpretations which arise from illogical sequencing of scientific facts by students.

The effect of yet another external factor on equilibrium was introduced in CBA 2, where trainees engaged in an SSSE concept activity to assess the effect of temperature on equilibrium by dipping a hot rod, and then a cold rod alternatively into a prepared blue solution of copper nitrate and hydrochloric acid in equilibrium. They observed that the solution of equilibrium mixture changed from blue to yellowishgreen with insertion of the hot rod (increased temperature) and from yellowish-green to blue in the presence of the cold rod (reduced temperature). Their explanation for the observed change was that the effect of heat on $\mathrm{Cl}^{-}$ions caused changes in the colour of the equilibrium mixture. In a control set up without $\mathrm{HCl}$ no changes occurred with increased or reduced temperatures. They further adjudged that under hot conditions $\mathrm{CuCl}_{4}{ }^{2-}(\mathrm{aq})$ ions were preferred while $\mathrm{Cu}\left(\mathrm{H}_{2} \mathrm{O}\right)_{4}{ }^{2+}(\mathrm{aq})$ was preferred under cold conditions and so dominated the presence of $\mathrm{CuCl}_{4}{ }^{2-}$ (aq) in their equilibrium mixture. These analyses were interesting to note, as they associated them with summations made by Le Chatelier. Their answer to a focus question for activity 2 was that, higher temperatures gave greater concentration of $\mathrm{CuCl}_{4}{ }^{2-}(\mathrm{aq})$ at equilibrium while lower temperatures gave greater concentrations of $\mathrm{Cu}\left(\mathrm{H}_{2} \mathrm{O}\right)_{4}{ }^{2+}(\mathrm{aq})$. In answer to an extension question on whether temperature affected the colours of all other solutions they gave scientific answers such as:

If the concentration of species are likely to change with temperature, then there could be colour change as some species will increase and others decrease. That will cause colours to change or appear.

If the concentration of one of the species on the product or reactant side increases more with temperature, the colour of the solution can change
If a coloured solution contains only one kind of species, there will be no colour change with increased or reduced heat. The change will come when maybe one or more of the substances reduces or increases in concentration. With only one coloured substance no change will occur, unless there are shifts from one end to another.

The trainees' comments translate to mean that in a closed system, the position of equilibrium will lie either to the right or left and will change once properties of substances in the equilibrium mixture change. It was also inferred from the trainees responses that since equilibrium constant at a working temperature does not change, equilibrium position will have to change to alleviate the system of stress and to keep a constant value for the equilibrium. This intimation was a demonstration of their cognitive growth about chemical equilibrium as associated terms such as concentration, equilibrium position, equilibrium shifts, equilibrium constant and Le Chatelier's principles were used in appropriate and correct contexts. This was evidence of the fact that the trainees had succeeded in expanding their science vocabulary. Besides, the concept-based instructional strategies or activities which were used supported the trainees to develop their understanding of and ability to use diverse learning skills such as prediction, reflection, observation, measurement, evaluation, and time management in small groups and whole class activities.

The mean scores for the pre- and post-assessments were 4.44 and 7.94 with standard deviations of 1.73 and 1.50 respectively. Statistical analysis of the scientific correctness of trainees' responses indicated that process and concept gains were made after their engagement with the SSSE through the CBAs. In order to test whether the gains were significant or not, paired sample t-test analysis of the trainees pre- and postassessments was carried out at a $95 \%$ confidence level. The outcome for the analysis is shown in Table 1.

Table 1. Paired samples t-test for the pre-and postassessment

\begin{tabular}{llllll}
\hline $\begin{array}{l}\text { Post-pre- } \\
\text { assessment }\end{array}$ & Mean & $\begin{array}{l}\text { Standard } \\
\text { deviation }\end{array}$ & $\mathrm{t}$ & $\mathrm{df}$ & $\begin{array}{l}\text { Sig. } \\
(2- \\
\text { tailed }) \\
.000\end{array}$ \\
\hline
\end{tabular}

Table 1 shows that significant gains were made after the trainees' engagement with the SSSE-CBAs at $\mathrm{t}(114)=1.9 \times 10^{-35} \mathrm{P}<0.000$, with post-assessment at $95 \%$ confidence interval of the difference. There was 
however no correlation (0.13) between the pre- and post-assessment scores for individuals. This implies that if an individual performed poorly or had naïve conceptions at the beginning of a lesson it did not translate into a continuous poor performance or good performance later. One's later performance is nonpredictive and will depend on one's attitude and efforts towards a study, though this was not assessed in this current research. A further assessment on the effect of the intervention, yielded a gain score of 0.64 , which is interpreted by Hake [14] as a medium gain range which lies between 0.3 to 0.7 . From Hake's scale it is obvious that the gain for this study (0.64) is very close to his definition of a high gain (0.7 to 1.0$)$ which suggests the effectiveness of an intervention, a strategy or teaching model. The interpretation here is that, the intervention was very effective in causing significant conceptual gains among the trainees.

Analysis of trainees' opinions about the CBA and SSSE through the questionnaires showed that they were happy with its use and enjoyed it. This enthusiasm to work with SSSE and subsequent conceptual gains were observed in studies that Adullah, Mohammed and Ismail [3] also carried out in Malaysia. The trainees in the current study identified gains in their learning about chemical equilibrium. They commented that the embedded strategy enabled them to graphically see the macroscopic process of equilibrium and how the change in concentration of $a$ species caused a quick and colourful change, to use their own words. They also intimated that the associated terms and effects of stress were well understood better this time than in earlier studies since they performed the micro activities themselves without fear of getting hurt from the plastic comboplate or minimal solutions and vividly saw the outcomes of their experimental procedures which were tiered. They found the equipment to be simple, versatile, useful, robust, interactive in nature, and the activities 'straight forward'. Thus, they worked without fear of breakages, and enjoyed sharing ideas with their colleagues. This enhanced their communicative skills. They added that it enhanced their predictive, interpretive, discussion, analytical and reflective skills [15]. Above all, they could now see in their mind's eye how the equilibrium processes and factors that affected them occurred; since their power of imagery had been enhanced. These comments reflect the trainees' perceptions of the many ways that the CBA and SSSE supported their development of macro-representational and conceptual understanding.

Results of this study provide evidence to support the growing body of literature that students hold misconceptions about many chemical concepts. It also emphasises the many benefits that practical activities offer and how adult learners develop many learning skills through it as intimated by Yildrim, Kurt and Ayas [9]. More importantly, it could be the first research on how to help teacher-trainees in a teaching university in sub-Saharan Africa to develop scientific conceptions about the dynamism of chemical equilibrium and how stress affects equilibrium position through vivid imageries linked with symbolic (equational) representations. Findings from the study may contribute to educators' understanding of some difficulties that students experience and thus help them in the selection of instructional methods. It must be noted that some of the trainees still held ACs after instruction as a $100 \%$ change was not achieved; nevertheless the intervention significantly contributed to the development of many learning skills which are crucial for the understanding of complex chemical concepts.

\section{Conclusion}

The simple small scale science equipment activities revealed trainees' conceptions about terms such as 'closed systems, dynamism, equilibrium and its influencing factors. They were able to develop lab, analytical, deductive, process and concept learning skills. They said that the activities were related in such a manner that the ideas gained in one activity facilitated the understanding of another. Besides, achievement of results were fast and fun. This implies that teachers can engage their students in similar small scale activities in the course of their lessons to enable them refute wrong conceptions and build more authentic conceptions, as was discovered in this study. The embedded conceptual strategy supported the trainees' use and understanding of various representations of the effect of stress and equilibrium shifts as well as how to use multiple representations to understand and communicate in science and chemistry in particular. If learners engage in learning by investigating, inquiring, collaborating, discussing and forming mental models in multiple representational modes, they will learn more meaningfully and make conceptual gains, as evidenced in this study.

\subsection{Recommendation}

The organisation of pre-diagnostic assessments would enable teachers to identify conceptual misunderstanding among their students and remediate them through appropriately designed activities. The activities in this study reinforced the development of not only trainees' concepts but process skills through images. Chemistry teacher trainees must understand chemical phenomena of everyday occurrences so that 
they can explain them from a chemical point of view in order to avoid the transfer of misconceptions of any type to future prospective unsuspecting chemistry students. It is hoped that other equally good teaching approaches would be adopted by teachers to enhance conceptual understanding of science principles.

\subsection{Implications}

The study has implications for science teachers in the design of simple interactive activities for their students, since such activities help students to form authentic ideas which are based on scientific models.

\subsection{Limitations}

A design with an experimental and control group could be adopted in another study since one-group pretest-intervention-post-test designs without control groups raise questions about the effectiveness of the intervention used.

\section{References}

[1] K. S. Taber and K. C. D. Tan, "The insidious nature of 'hard core' alternative conceptions: Implications for the constructivist research programme of patterns in high school students' and pre-service teachers' thinking about ionisation energy," International Journal of Science Education, vol. 33, no. 2, pp. 259-297, 2011.

[2] K. S. Taber, Chemical misconceptions- Prevention, diagnosis and cure. Volume 1: Theoretical background, London: Royal Society of Chemistry, 2002.

[3] M. Abdullah, H. Mohamed and Z. Ismail, "Development of microscale chemistry experimentation for secondary school students in Malyasia (Form Five)," Chemical Education Journal, vol. 10, no. 2, pp. 1-8, 2008.

[4] A. H. Haider and A. K. Al Naqabi, "Emiratii High School students' understandings of stoichiometry and the influence of metacognition on their understanding," Research in Science and Technological Education, vol. 26, no. 2, pp. 215227,2008 .

[5] Z. Zakaria, L. Latip and S. Tantayanon, "Organic chemistry practices for undergraduates, using a small lab kit," Procedia-Social and Behavioural Sciences, vol. 59, no. 1, pp. 508-514, 2012.

[6] I. Bilgin, E. Uzuntiryaki and O. Geban, "Students' misconceptions on the concept of chemical equilibrium," Education and Science, vol. 29, no. 127, pp. 10-17, 2003.

[7] J. R. Locaylocay, Changes in college students' conceptions of chemical equilibrium, Amsterdam: Vrije University, 2006.
[8] R. Hanson, "Chemistry teacher trainees' perceptions of chemical equilibrium," The International Journal of Humanities and Social Studies, vol. 4, no. 1, pp. 80-88, 2016.

[9] N. Yildirim, S. Kurt and A. Ayas, "The effect of worksheets on students' achievement in chemical equilibrium," Turkish Science Education, vol. 8, no. 3, pp. 44-58, 2011.

[10] D. L. Schmidt, B. W. Saigo and J. I. Stephans, Conceptual change model: The CCM Handbook, Missouri: Saiwood Publications, 2006.

[11] V. Munde, C. Vlaskamp, B. Maes and W. Ruijssenaars, "Physiological measurement as validation of alertness observations: An exploratory case study of three individuals with profound intellectual and multiple disabilities," Intellectual and Development Disabilities, vol. 50, no. 4, pp. 300-310, 2012.

[12] M. H. Yoo, H. G. Hong and H. Yoon, "The effect of small-scale chemistry lab programme on students' science achievement, related affective domain and academic selfefficacy in high school chemistry," in Paper presented at International South Education Conference, Singapore, 2006.

[13] J. Gooding and B. Metz, "From misconceptions to conceptual change,” The Science Teacher, pp. 34-37, 2011.

[14] R. R. Hake, "Interactive-engagement versus traditional methods: A six-thousand-student survey of mechanics test data for introductory physics courses," American Journal of Physics, vol. 66, no. 1, pp. 64-74, 1998.

[15] R. Hanson and S. Acquah, "Enhancing concept understanding through the use of micro chemistry equipment and collaborative activities," Journal of Education and Practice, vol. 5, no. 12, pp. 120-130, 2014. 
Appendix A: Pre-assessment items (based on SSSE-CBA)

1. What could be the effect of change in the concentration of reactants on the following chemical equilibrium:

$\mathrm{Cu}\left(\mathrm{H}_{2} \mathrm{O}\right)_{4}{ }^{2+}(\mathrm{aq})+4 \mathrm{Cl}^{-}(\mathrm{aq}) \rightleftharpoons \mathrm{CuCl}_{4}{ }^{2-}(\mathrm{aq})+4 \mathrm{H}_{2} \mathrm{O}$

(1)

2. What would be the effect of temperature on the chemical equilibrium in question 1 ?

3. Would the reaction stop or continue after equilibrium is reached?

4. Predict the effect of reduction of concentration of the reactants on the chemical equilibrium: $\mathrm{Cu}\left(\mathrm{H}_{2} \mathrm{O}\right)_{4}{ }^{2+}(\mathrm{aq}) \quad+4 \mathrm{Cl}^{-}(\mathrm{aq}) \rightleftharpoons \mathrm{CuCl}_{4}{ }^{2-}(\mathrm{aq})+$ $4 \mathrm{H}_{2} \mathrm{O}(1)$

Appendix B: Trainees conceptions from the pre-lab exercise on chemical equilibrium $(\mathrm{N}=115)$

\begin{tabular}{|l|l|l|l|}
\hline Concept & Wrong concepts & $\begin{array}{l}\text { Wrong } \\
\text { response }\end{array}$ & $\begin{array}{l}\% \text { Wrong } \\
\text { response }\end{array}$ \\
\hline $\begin{array}{l}\text { Factors for } \\
\text { equilibrium } \\
\text { shifts }\end{array}$ & $\begin{array}{l}\text {-reduction of a } \\
\text { solid affects } \\
\text { equilibrium } \\
\text { constant } \\
\text {-reduction of a } \\
\text { solid affects } \\
\text { mole ratio } \\
\text {-removal of } \\
\text { solid reactant } \\
\text { will make } \\
\text { products give } \\
\text { back more } \\
\text { reactants } \\
\text { - when a system } \\
\text { reaches } \\
\text { equilibrium, no } \\
\text { further changes } \\
\text { occur }\end{array}$ & 58 & 53 \\
\hline $\begin{array}{l}\text {-temperature } \\
\text { change has no } \\
\text { effect on } \\
\text { equilibrium } \\
\text { systems as } \\
\text { product yield is } \\
\text { constant } \\
\text {-increase in } \\
\text { temperature } \\
\text { favours forward } \\
\text { reaction } \\
\text { - increase in } \\
\text { temperature } \\
\text { results in a shift } \\
\text { to the right as } \\
\text { the kinetic } \\
\text { energy of the } \\
\text { reacting } \\
\text { molecules } \\
\text { increase }\end{array}$ & 69 & 48 \\
\hline
\end{tabular}

\begin{tabular}{|l|l|l|l|}
\hline $\begin{array}{l}\text { Concentrati } \\
\text { on and } \\
\text { amount of } \\
\text { substance }\end{array}$ & $\begin{array}{l}\text {-Increasing } \\
\text { reactants } \\
\text { increase } \\
\text { concentration } \\
\text {-amount of } \\
\text { substance can } \\
\text { be } \\
\text { interchanged } \\
\text { with } \\
\text { concentration } \\
\text { - Increase in } \\
\text { concentration } \\
\text { of reactants } \\
\text { will increase } \\
\text { concentration } \\
\text { of products } \\
\text { - } \\
\text { Concentration } \\
\text { affects } \\
\text { equilibrium } \\
\text { position to the } \\
\text { right as it } \\
\text { hastens the } \\
\text { reaction } \\
\text { - The value of } \\
\text { Keq is } \\
\text { commensurate } \\
\text { with product } \\
\text { change } \\
\text {-volume of } \\
\text { solution does } \\
\text { not affect } \\
\text { concentration } \\
\text { as the solid } \\
\text { remains the } \\
\text { same } \\
\text { - } \\
\text { concentration } \\
\text { is the same as } \\
\text { amount of } \\
\text { substance }\end{array}$ & $\begin{array}{l}\text {-lively, active, } \\
\text { works hard, } \\
\text { busy, strong }\end{array}$ & 64 \\
\hline
\end{tabular}

Appendix C: The Concept Based Activities (CBA) using Small Scale Science Equipment (SSSE)

CBA 1: The effect of changed concentration on equilibrium position

i) Place three spatulas of solid $\mathrm{Cu}\left(\mathrm{NO}_{3}\right)_{2} \cdot 3 \mathrm{H}_{2} \mathrm{O}$ in two Wells $\mathrm{A}[1]$ and $\mathrm{A}[2]$ and form a solution by adding 6 
drops of water to each. Add $\mathrm{HCl}$ to Well $\mathrm{A}[2]$.

For every drop of $\mathrm{HCl}$ added to Well $\mathrm{A}[2]$, equivalent drops of water must be added to Well A[1] for comparison and dilution effects. Colour changes should be observed and changes discussed. (Do not discard your solutions. They will be used in Activity 2).

ii) From the following list of reagents choose one that will cause a blue solution of $\mathrm{Cu}\left(\mathrm{NO}_{3}\right)_{2} \cdot 3 \mathrm{H}_{2} \mathrm{O}$ to turn the same colour that you observed upon the addition of $\mathrm{HCl}$ :

$\mathrm{HNO}_{3}, \mathrm{NaOH}, \mathrm{KOH}, \mathrm{H}_{3} \mathrm{PO}_{4}, \mathrm{H}_{2} \mathrm{SO}_{4}$.

Discuss and record your answer with reasons.

CBA 2: The effect of temperature on equilibrium position

You will need ice cubes and a micro burner with methylated spirit in it. Be careful with the methylated spirit. If you have your solution from CBA 1, you will use it for this activity.

i) Prepare an equilibrium mixture as you did in CBA 1 if you discarded your solution. Pass a glass rod through the flame of your microburner and put it into Well A[2] and observe the colour changes which appear. Quickly dry the rod, dip it into the ice cubes or ice cold water and dip it into Well A[2] again. Observe the colour change. Discuss your observation with your colleague and record your conclusion.

ii) Explain the species that are preferred under hot conditions and that preferred under cold conditions.

iii) Repeat the activity using the solution in Well A[1] with the cold and hot rod. Discuss your observation.

Were changes observed like that as occurred in Well A[2] or not? Explain

\section{Appendix D: Learning Skills Observation Schedule}

The tick sign $(\sqrt{ })$ is used when a desired behaviour is observed. When the behaviour is only partially observable, use the designed sign $( \pm)$. When a desired behaviour is not observed at all, use a negative sign (-).

\section{Learning Skills Observation Schedule}

\begin{tabular}{|c|c|c|}
\hline Trainees' behaviour & $\begin{array}{l}\text { Activity } \\
1\end{array}$ & $\begin{array}{l}\text { Activity } \\
2\end{array}$ \\
\hline $\begin{array}{l}\text { Contribute to pre-activity } \\
\text { discussions \& connects to the } \\
\text { activity } \\
\text { Form groups \& demonstrate } \\
\text { acquisition of lab \& process skill } \\
\text { Groups interact with each other } \\
\text { and facilitator as expected with } \\
\text { Working } \\
\text { apparatus/materials for skills } \\
\text { acquisition } \\
\text { Discussion of outcomes in small } \\
\text { groups } \\
\text { Understanding of procedures for } \\
\text { the activities } \\
\text { Exhibition and acquisition of } \\
\text { manipulative, concept and } \\
\text { process skills } \\
\text { Work within the allotted time } \\
\text { Relate activities with theory in a } \\
\text { logical manner } \\
\text { Use concepts, terms and } \\
\text { language with comprehension } \\
\text { Extend concept to demonstrate } \\
\text { permanent learning }\end{array}$ & & \\
\hline
\end{tabular}

\section{Appendix F: Post-Assessment Items}

1. For an equilibrium mixture: $\left[\mathrm{CoCl}_{4}\right]^{2-}(\mathrm{aq})+$ $6 \mathrm{H}_{2} \mathrm{O}(\mathrm{l}) \rightleftharpoons\left[\mathrm{Co}\left(\mathrm{H}_{2} \mathrm{O}\right)_{6}\right]^{2+}(\mathrm{aq})+4 \mathrm{Cl}^{-}$ What would you observe if two sealed tubes of the mixture are swapped between cold and hot water?

2. Carry out the 20-minute activity with the materials provided to observe equilibrium shifts and answer all questions which follow.

a) Add 3 drops of $0.2 \mathrm{M} \mathrm{FeCl}_{3}$ in a $50 \mathrm{~mL}$ beaker, after which you will add 2 drops of $0.2 \mathrm{M} \mathrm{KSCN}$ and swirl. The propette should be used for the drops of solutions.

b) Add distilled water to the beaker to dilute the dark colour to light orange and swirl.

c) Use 5 Wells $A[1]$ to E[1]. Fill to about $3 / 4$ full.

d) Well A[1] serves as a control

e) Add 2 drops of $0.2 \mathrm{M} \mathrm{Fe}\left(\mathrm{NO}_{3}\right)_{3}$ to Well $\mathrm{B}$ [1]

f) Add 2 drops of $0.2 \mathrm{M} \mathrm{KCl}$ to Well C[1] 
g) Add 2 drops of $0.2 \mathrm{M} \mathrm{KSCN}$ to Well D [1]

h) Add 2 drops of $6.0 \mathrm{M} \mathrm{NaOH}$ to Well E[1]

i) Examine Wells $\mathrm{B}[1]$ to $\mathrm{E}[1]$ in comparison to $\mathrm{A}[1]$

3. Using the equation, find the ion creating stress in each tube that had an equilibrium shift

4. Decide whether or not an equilibrium shift occurred in each tube and indicate the direction of equilibrium shifts with arrows

5. Explain your observation in Well E[1]

Appendix G: Questionnaire to assess trainees' opinions

This evaluation sheet is to assess your impressions about the SSSE and CBA and how they impacted on your understanding about Chemical Equilibrium. Read each item carefully and agree or disagree with the statements provided by making a tick $(\sqrt{ })$ with respect to the rating scale provided as points.

$\mathrm{SD}=$ Strongly Disagree (1) $\mathrm{D}=$ Disagree (2) $\mathrm{N}=\mathrm{Not}$ sure (3) $\mathrm{A}=$ Agree (4) $\mathrm{SA}=$ Strongly Agree (5)

\begin{tabular}{|c|c|c|c|c|c|c|}
\hline Item & Statements & SD & D & $\mathbf{N}$ & $\mathbf{A}$ & $\mathbf{S A}$ \\
\hline 1 & $\begin{array}{l}\text { The SSSE was fun } \\
\text { and easy to use }\end{array}$ & & & & & \\
\hline 2 & $\begin{array}{l}\text { Past teaching methods } \\
\text { made it difficult to } \\
\text { understand concept } \\
\text { 'equilibrium' }\end{array}$ & & & & & \\
\hline 3 & $\begin{array}{l}\text { Using the SSSE } \\
\text { enhanced my } \\
\text { understanding of } \\
\text { concepts about the } \\
\text { term 'dynamism' }\end{array}$ & & & & & \\
\hline 4 & $\begin{array}{l}\text { The activity enhanced } \\
\text { my understanding of } \\
\text { how stress affects the } \\
\text { position of } \\
\text { equilibrium }\end{array}$ & & & & & \\
\hline 5 & $\begin{array}{l}\text { I have had exposure } \\
\text { to simpler, active } \\
\text { ways of conducting } \\
\text { activities }\end{array}$ & & & & & \\
\hline 6 & $\begin{array}{l}\text { The CBA procedures } \\
\text { were simple and easy } \\
\text { to translate into } \\
\text { practical activity } \\
\text { without directions } \\
\text { from the teacher }\end{array}$ & & & & & \\
\hline 7 & $\begin{array}{l}\text { My learning skills } \\
\text { were not affected by } \\
\text { the SSSE concept }\end{array}$ & & & & & \\
\hline
\end{tabular}

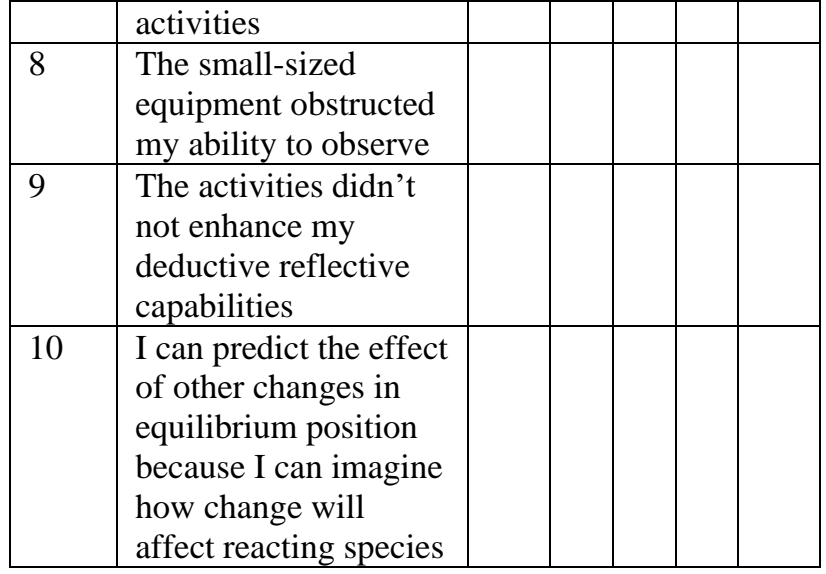

11. Please write down other comments that you wish to make which are not represented in the statements provided. 